\title{
miRNA-328 overexpression confers cisplatin resistance in non-small cell lung cancer via targeting of PTEN
}

\author{
CHUNMEI WANG ${ }^{1}$, SHIJUN WANG ${ }^{2}$, FENG'E MA $^{3}$ and WEIDAN ZHANG ${ }^{4}$ \\ Departments of ${ }^{1}$ Respiration, ${ }^{2}$ Emergency, ${ }^{3}$ Outpatients and ${ }^{4}$ Intensive Medicine, \\ Dezhou People's Hospital, Dezhou, Shandong 253014, P.R. China
}

Received November 3, 2017; Accepted April 12, 2018

DOI: $10.3892 / \mathrm{mmr} .2018 .9478$

\begin{abstract}
Chemotherapy resistance, the molecular mechanism of which is complex and has not been fully understood, poses a major challenge in the treatment of patients with non-small cell lung cancer (NSCLC). The dysregulation of microRNAs (miRs) has been reported to serve a pivotal role in the development of cancer and drug resistance. In the present study, reverse transcription-quantitative polymerase chain reaction analysis revealed a significant increase in miR-328 and a significant decrease in phosphatase and tensin homolog (PTEN) mRNA expression levels within tumor tissues from patients with cisplatin-resistant NSCLC compared with those of cisplatin-sensitive NSCLC patients. In addition, there was a negative correlation between PTEN mRNA and the miR-328 expression levels. In addition, higher miR-328 expression levels, and lower PTEN mRNA and protein expression levels, were detected in cisplatin-resistant A549 (A549rCDDP) cells when compared with in their parental cells. A549rCDDP cells demonstrated significantly higher cell viability compared with A549 cells following treatment with all concentrations of cisplatin tested $(2,4,6$ and $8 \mu \mathrm{M})$. Additionally, transfection of miR-328 inhibitor significantly increased PTEN mRNA and protein expression levels. Furthermore, the present study predicted and confirmed PTEN, a well-known tumor suppressor, as a direct target of miR-328 in NSCLC cells via the online tool MiRanda and a dual luciferase assay, respectively. Cell viability assay and flow cytometry analysis demonstrated that inhibition of miR-328 also induced cellular apoptosis and decreased cell proliferation in A549rCDDP cells treated with cisplatin. In conclusion, these results suggested that abnormal expression of miR-328 may contribute to cisplatin resistance in NSCLC, and may be considered to be a novel therapeutic
\end{abstract}

Correspondence to: Dr Weidan Zhang, Department of Intensive Medicine, Dezhou People's Hospital, 1 Sanba Road, Dezhou, Shandong 253014, P.R. China

E-mail: zhangweidandzph@outlook.com

Key words: microRNA-328, cisplatin resistance, non-small cell lung cancer, phosphatase and tensin homolog target and indicator for the treatment and prognosis of patients with NSCLC treated with cisplatin-based chemotherapy.

\section{Introduction}

Lung cancer is a common type malignant tumor with the highest incidence rate worldwide compared with other types of cancers (1), and $\sim 80 \%$ of lung cancer cases may be classified as non-small cell lung cancer (NSCLC) (2). Chemotherapy has been reported to improve the survival rate of patients with NSCLC and is considered to be a first-line treatment following surgery (3). Cisplatin-based chemotherapy is frequently used in the clinical treatment of cancer (4). Patients may respond well to cisplatin at the beginning of treatment; however, the majority of patients develop resistance to cisplatin, resulting in therapy failure (5). Thus, revealing the molecular mechanism underlying the development of cisplatin resistance is required to improve the treatment outcome of patients with lung cancer.

By binding to the 3' untranslated region (UTR) of target mRNAs, microRNAs (miRNA/miRs) are able to regulate gene expression at the transcriptional and translational levels (6). Through the downregulation of certain proteins, miRNAs have been associated with numerous cellular behaviors and the pathogenesis of a number of diseases $(7,8)$. During the initiation and development of cancer, the dysregulation of miRNAs has been frequently observed to lead to alterations in the expression of oncogenes or tumor suppressors (9). In-depth studies on the regulatory networks of miRNAs in cancer may provide novel prognostic predictors and therapeutic approaches, beneficial for patients with cancer (10). miR-328 has been reported to promote the progression of various cancer types, including breast and hepatocellular cancers $(11,12)$. In NSCLC, elevations in miR-328 expression levels were associated with brain metastasis (13); however, the role of miR-328 in the development of cisplatin resistance in NSCLC remains unclear.

Phosphatase and tensin homolog (PTEN) is a well-characterized phosphatase, as well as a tumor suppressor, which may undergo mutations in a variety of cancers (14). PTEN serves its tumor suppressor role by negatively regulating the phosphatidylinositol 3-kinase (PI3K)-RAC- $\alpha$ serine/threonine-protein kinase (AKT) signaling pathway (15). The expression of PTEN is tightly controlled by noncoding RNAs, protein-protein interactions and protein modifications (16). 
Alterations in the expression or activity of PTEN may lead to the uncontrolled activation of the PI3K-AKT signaling pathway, which may promote the progression of cancer and induce drug resistance $(17,18)$.

In the present study, miR-328 expression levels were elevated, while the mRNA expression levels of PTEN were decreased in tumor tissues obtained from patients with cisplatin-resistant NSCLC, compared with patients with cisplatin-sensitive NSCLC. In addition, there was a negative correlation between PTEN mRNA and miR-328 expression levels in the tumor tissues of patients with NSCLC. The present study reported an increase in miR-328 expression levels in cisplatin-resistant A549 (A549rCDDP) cells) compared with parental cells. Furthermore, PTEN was predicted to be a direct target of miR-328 in NSCLC cells via computational and dual-luciferase methods. Additionally, the present study proposed that the exposure of miR-328-silenced A549rCDDP cells to cisplatin may be associated with cellular apoptosis and inhibition of cell growth, indicating that miR-328 may serve a central role in mediating cisplatin-resistance exhibited by A549rCDDP cells. The present study demonstrated that miR-328 may function in cisplatin resistance in NSCLC by targeting PTEN.

\section{Patients and methods}

Patients. A total of 58 tumor tissue samples were collected from 35 patients with cisplatin-sensitive NSCLC and 23 patients with cisplatin-resistant NSCLC; 47 of the patients were aged $<60$-years-old and 11 of the patients were aged $\geq 60$-years old. A total of 42 male patients and 16 female patients participated in the present study. Patients were eligible if they had no history of prior chemotherapy and radiotherapy. The cisplatin-sensitive patients were defined as sensitive to cisplatin-based chemotherapy following surgery; cisplatin-resistant patients were defined as non-responsive to cisplatin-based chemotherapy following surgery. The response to cisplatin-based chemotherapy was defined in accordance with the Response Evaluation Criteria in Solid Tumors (RECIST) criteria (19), and patients were categorized into two different groups: Cisplatin-sensitive and cisplatin-resistant. Patients in the sensitive group exhibited a complete response (CR, as indicated in the RECIST criteria). Patients in the resistant group exhibited persistent disease [PR (Partial response), SD (Stable disease) or PD, as indicated in the RECIST criteria]. According to the WHO classification of lung cancer (20), patients were divided into the well-intermediate and the poor differentiation groups.

All samples were obtained from Dezhou People's Hospital (Dezhou, China) between April 2013 and June 2016. Written informed consent was provided by all patients prior to surgery. All participants did not receive radiotherapy or chemotherapy prior to surgery. The present study was approved by the Ethics Committee of Dezhou People's Hospital (approval no. DZPH-2013-16). Tissue samples were immediately frozen at $-80^{\circ} \mathrm{C}$ prior to protein and RNA extraction.

Cell culture and agents. The human NSCLC cell line A549 was purchased from the American Type Culture Collection (Manassas, VA, USA). The cisplatin-resistant A549 sub-line
A549rCDDP was purchased from the Cancer Hospital of Peking Union Medical College, Chinese Academy of Medical Sciences (Beijing, China). The cell line was cultured in RPMI-1640 medium (Gibco; Thermo Fisher Scientific, Inc., Waltham, MA, USA) containing $10 \%$ fetal bovine serum (Hyclone; GE Healthcare Life Sciences, Logan, UT, USA) in an incubator at $37^{\circ} \mathrm{C}$ with $5 \% \mathrm{CO}_{2}$. For the A549rCDDP cells, the medium also contained $2 \mathrm{mg} / \mathrm{l}$ cisplatin (Selleck Chemicals, Houston, TX, USA). For the analysis of cisplatin response, increasing concentrations of cisplatin (2, 4, 6 and $8 \mu \mathrm{M})$ were added into the culture media of A549 cells and A549rCDDP cells at $37^{\circ} \mathrm{C}$ for $48 \mathrm{~h}$, which were subsequently subjected to further experimentation.

Cell transfection. For the cell transfection assay, $1 \times 10^{6}$ A549 or A549rCDDP cells were treated with $50 \mathrm{nM}$ miR-328 inhibitor (5'-GACCGGGAGAGACGGGAAGGCA-3') or miR-NC (negative control) inhibitor (NC, 5'-GGCAAGACG AAACGAGACGACA-3' (Shanghai GenePharma Co., Ltd., Shanghai, China) in $1 \mu \mathrm{l}$ Lipofectamine ${ }^{\circledR} 2000$ (Invitrogen; Thermo Fisher Scientific, Inc.), according to the manufacturer's protocols. For the control group, cells were neither treated with miR-NC or miR-328 inhibitor.

$R N A$ extraction and reverse transcription-quantitative polymerase chain reaction ( $R T-q P C R)$. Total RNA from tissues and cells was extracted using an miRNeasy Mini kit (Qiagen, Inc., Valencia, CA, USA) following the manufacturer's protocol. The synthesis of first-strand cDNA was performed with an M-MLV kit (GE Healthcare Life Sciences) following the manufacturer's protocol. Subsequently, qPCR was performed on a CFX96 system (Bio-Rad Laboratories, Inc., Hercules, CA, USA) using SYBR ${ }^{\circledR}$ Premix Ex Taq (Takara Bio, Inc., Otsu, Japan). GAPDH and U6 served as internal controls for and mRNA and miRNA measurements, respectively. The reaction conditions were as follows: $95^{\circ} \mathrm{C}$ for $10 \mathrm{~min}, 40$ cycles at $95^{\circ} \mathrm{C}$ for $15 \mathrm{sec}$ and at $60^{\circ} \mathrm{C}$ for $1 \mathrm{~min}$. The relative expression levels of the indicated genes were calculated using the of $2^{-\Delta \Delta \mathrm{Cq}}$ method (21). The sequences for primers were: miR-328 forward, 5'GCTGGCCCTCTCTGCCC3' and reverse, 5'CGT CAGATGTCCGAGTAGAGG3'; PTEN forward, 5'CGGTGT CATAATGTCTTTCAGC3' and reverse, 5'TGAAGGCGT ATACAGGAACAAT3'; GAPDH forward, 5'AGAAGGCTG GGGCTCATTTG3' and reverse, 5'AGGGGCCATCCACAG TCTTC3'; and U6 forward, 5'CTCGCTTCGGCAGCACA3' and reverse, 5'AACGCTTCACGAATTTGCGT3'.

Western blot analysis. GAPDH (cat. no. 5174; 1:5,000) and PTEN antibodies (cat. no. 9188, 1:1,000) were obtained from Cell Signaling Technology, Inc. (Danvers, MA, USA). Secondary antibodies against rabbit (HRP-conjugated Goat polyclonal Secondary Antibody to Rabbit IgG; ab97080; 1:10,000) and mouse (HRP-conjugated Goat polyclonal Secondary Antibody to Mouse IgG; ab97040; 1:10,000) were purchased from Abcam (Cambridge, MA, USA). Total protein from A549 and A549rCDDP cell lysates was prepared using radioimmunoprecipitation assay lysis buffer (Beyotime Institute of Biotechnology, Haimen, China). The protein lysates were quantified using Pierce BCA Protein Assay kit (Thermo Fisher Scientific, Inc.) according to manufacturer's 
Table I. Expression of miR-328 and PTEN in NSCLC tissues.

\begin{tabular}{|c|c|c|c|c|c|}
\hline Factor & No. cases & $\begin{array}{l}\text { miRNA-328, mean } \pm \\
\text { standard deviation }\end{array}$ & P-value & $\begin{array}{c}\text { PTEN, mean } \pm \\
\text { standard deviation }\end{array}$ & P-value \\
\hline Sex & & & 0.38 & & 0.67 \\
\hline Male & 42 & $1.51 \pm 0.72$ & & $0.86 \pm 0.32$ & \\
\hline Female & 16 & $1.32 \pm 0.52$ & & $0.90 \pm 0.32$ & \\
\hline Age, years & & & 0.39 & & 0.66 \\
\hline$<60$ & 47 & $1.49 \pm 0.70$ & & $0.86 \pm 0.32$ & \\
\hline$\geq 60$ & 11 & $1.30 \pm 0.55$ & & $0.91 \pm 0.30$ & \\
\hline Tumor size, $\mathrm{cm}$ & & & 0.06 & & 0.98 \\
\hline$\geq 5$ & 21 & $1.68 \pm 0.51$ & & $0.87 \pm 0.32$ & \\
\hline$<5$ & 37 & $1.33 \pm 0.73$ & & $0.88 \pm 0.32$ & \\
\hline Histological grade & & & 0.00 & & $<0.001$ \\
\hline Well-intermediate differentiation & 22 & $1.10 \pm 0.26$ & & $1.05 \pm 0.28$ & \\
\hline Poor differentiation & 36 & $1.67 \pm 0.76$ & & $0.77 \pm 0.32$ & \\
\hline
\end{tabular}

NSCLC, non-small cell lung cancer; PTEN, phosphatase and tensin homolog; miRNA, microRNA.

protocol. Then, $15 \mu \mathrm{g}$ proteins were isolated and then separated by $8 \%$ SDS-PAGE and transferred onto polyvinylidene difluoride membranes (EMD Millipore, Billerica, MA, USA). The membranes were then blocked with $5 \%$ non-fat milk for $0.5 \mathrm{~h}$ at room temperature, washed with Tris-buffered saline with Tween-20 (0.1\%) and incubated with the aforementioned primary antibodies at $4{ }^{\circ} \mathrm{C}$ overnight, followed by incubation with the secondary antibodies at room temperature for $1 \mathrm{~h}$. The bands were visualized using Pierce ECL Western Blotting Substrate (Thermo Fisher Scientific, Inc.). GAPDH served as an internal expression control.

Cell viability assay. The inhibitory effect of cisplatin was investigated using a Cell Counting kit-8 (CCK8; Dojindo Molecular Technologies, Inc., Kumamoto, Japan). Following transfection with miR-NC inhibitor or miR-328 inhibitor or untransfected, 1,000 A549 or A549rCDDP cells were seeded in each well of 96-well plates in the RPMI-1640 medium containing vehicle (DMSO) or different concentrations of cisplatin $(0.25,0.5,1,2,4$ or $8 \mu \mathrm{M})$ then incubated for $72 \mathrm{~h}$ at $37^{\circ} \mathrm{C}$. Following incubation for $0,24,48$ or $72 \mathrm{~h}$, $10 \mu \mathrm{l} \mathrm{CCK} 8$ solution was added into each well and the cells were incubated for a further $2 \mathrm{~h}$ at $37^{\circ} \mathrm{C}$. The absorbance of each well at $450 \mathrm{~nm}$ was measured with a microplate reader (Bio-Rad Laboratories, Inc.).

Cellular apoptosis assay. Cellular apoptosis in response to treatment with cisplatin $(1 \mu \mathrm{M})$ was measured using an Annexin-V/Dead Cell Apoptosis kit (Invitrogen; Thermo Fisher Scientific, Inc.) following the manufacturer's protocols. Briefly, following treatment, A549rCDDP cells were harvested by trypsinization and suspended in Annexin $\mathrm{V}$ binding buffer; propidium iodide and Annexin V-fluorescein isothiocyanate were then added to the cell suspensions and incubated for $15 \mathrm{~min}$ at room temperature. The cells were analyzed using a BD FACSCalibur flow cytometer (BD Biosciences, Franklin Lakes, NJ, USA). The cells positive for Annexin V staining were considered as apoptotic cells following analysis using FlowJo version 10.2 (FlowJo LLC, Ashland, OR, USA).

Dual-luciferase reporter assay. Prediction of miR-328 target genes was carried out on miRanda (http://34.236.212.39/microrna/home.do). For the preparation of A549 cDNA, A549 RNA was extracted using TRIzol (Invitrogen; Thermo Fisher Scientific, Inc.) according to manufacturer's protocol and then reverse transcribed to cDNA with PrimeScript ${ }^{\mathrm{TM}}$ II 1st Strand cDNA Synthesis kit (Takara Bio, Inc.) following the manufacturer's protocol. The wild type PTEN 3'UTR (PTEN 3'UTR WT) was amplified from the cDNA of A549 cells using TaKaRa Ex Taq ${ }^{\circledR}$ DNA Polymerase. kit (Takara Bio, Inc.). The thermo cycle conditions were denaturation at $98^{\circ} \mathrm{C}$ for $10 \mathrm{sec}$, annealing at $55^{\circ} \mathrm{C}$ for $30 \mathrm{sec}$, followed by elongation at $72^{\circ} \mathrm{C}$ for $60 \mathrm{sec}$, repeated for 30 cycles. It was then inserted into $\mathrm{XbaI}$ site of the pGL-3 vector (Promega Corporation, Madison, WI, USA). A mutated PTEN 3'UTR (PTEN 3'UTR Mut) was created using a site-directed mutagenesis kit (Agilent Technologies, Inc., Santa Clara, CA, USA) according to the manufacturer's protocols. Then, $1 \times 10^{6}$ A549 cells were cotransfected with $2 \mu \mathrm{g}$ pGL3-PTEN 3'UTR WT or pGL3-PTEN 3'UTR Mut, $50 \mathrm{nM}$ miR-328 mimics (5'-CUGGCCCUCUCUGCCCUUCCG U-3') or miR-NC (5'-AUUGGAACGAUACAGAGAAGA-3') (Shanghai GenePharma Co., Ltd.) and internal control Renilla plasmid (Promega Corporation) using Lipofectamine ${ }^{\circledR} 2000$ (Invitrogen; Thermo Fisher Scientific, Inc.). Following transfection for $24 \mathrm{~h}$, luciferase and Renilla activities were detected using a Dual Luciferase Reporter Assay kit (Promega Corporation) following the manufacturer's protocols.

Statistical analysis. All experiments were repeated 3 times and all statistical analyses were performed using GraphPad Prism 5.0 (GraphPad Software, Inc., La Jolla, CA, USA). All data are presented as the mean \pm standard deviation. The correlation analysis was carried out using Pearson Correlation 
Table II. Patient characteristics in cisplatin-responsive and non-responsive.

\begin{tabular}{|c|c|c|c|}
\hline Factor & Cisplatin-responsive & Cisplatin-nonresponsive & P-value \\
\hline Sex & & & 1.00 \\
\hline Male & 25 & 17 & \\
\hline Female & 10 & 6 & \\
\hline Age, years & & & 0.74 \\
\hline$<60$ & 29 & 18 & \\
\hline$\geq 60$ & 6 & 5 & \\
\hline Tumor size, $\mathrm{cm}$ & & & 0.58 \\
\hline$\geq 5$ & 14 & 7 & \\
\hline$<5$ & 21 & 16 & \\
\hline Histological grade & & & 1.00 \\
\hline Well-intermediate differentiation & 13 & 9 & \\
\hline Poor differentiation & 22 & 14 & \\
\hline
\end{tabular}

analysis. Differences between two groups were compared using Student's t-tests. Differences among $>2$ groups were analyzed with one-way analysis of variance followed by Newman-Keuls analysis. Comparison of patient characteristics was achieved using the $\chi^{2}$ test. $\mathrm{P}<0.05$ was considered to indicate a statistically significant difference.

\section{Results}

miR-328 expression levels are elevated in tumor tissues from patients with cisplatin-resistant NSCLC and are negatively correlated with PTEN mRNA expression levels. The present study investigated the expression of miR-328 and PTEN in the tissues of patients with NSCLC. As presented in Table I, the expression of miR-328 was not correlated with every one of the listed characteristics: $\operatorname{Sex}(\mathrm{P}=0.38)$, age $(\mathrm{P}=0.39)$ or tumor size $(\mathrm{P}=0.06)$. In addition, no significant differences were reported in the expression levels of PTEN between the characteristics of sex $(\mathrm{P}=0.67)$, age $(\mathrm{P}=0.66)$ or tumor size $(\mathrm{P}=0.98)$. Furthermore, there were significant differences in the expression levels of miR-328 $(\mathrm{P}=0.00)$ and PTEN $(\mathrm{P}=0.00)$ between the well-intermediate and the poor differentiation groups.

Additionally, the characteristics of patients in the cisplatin-responsive and non-responsive groups were analyzed in the present study. As presented in Table II, there were no significant differences in the characteristics of sex $(\mathrm{P}=1.00)$, age $(\mathrm{P}=0.74)$, tumor size $(\mathrm{P}=0.58)$ or histological grade $(\mathrm{P}=1.00)$ between cisplatin-responsive and non-responsive groups.

To investigate the role of miR-328 in the development of cisplatin resistance in NSCLC, RT-qPCR was employed to detect whether there were differences in miR-328 expression levels between tumor tissues from patients with cisplatin-sensitive and cisplatin-resistant NSCLC. A significant increase in miR-382 expression levels was detected in the cisplatin-resistant tumor tissues compared with the cisplatin-sensitive tumor tissues $(\mathrm{P}<0.0001$; Fig. 1A). Loss of PTEN has frequently been reported to contribute to chemoresistance, particularly cisplatin-resistance in NSCLC (22). As expected, the present study observed a significant decrease in PTEN mRNA expression levels within the tumor tissues from patients with cisplatin-resistant NSCLC compared with the cisplatin-sensitive tumor tissues $(\mathrm{P}<0.0001$; Fig. 1B). In addition, there was a significant negative correlation between miR-328 and PTEN mRNA expression levels in the NSCLC tumor tissues (Fig. 1C), suggesting an underlying regulatory association between miR-328 and PTEN in NSCLC.

Dysregulation of miR-328 and PTEN expression is involved in the development of cisplatin resistance in a cell model. In order to investigate the role of miR-328 in cisplatin resistance, the A549 cell line and its cisplatin-resistant sub-line A549rCDDP were employed in the present study. Compared with A549 cells, A549rCDDP cells were relatively insensitive to increasing concentrations of cisplatin $(2,4,6$ and $8 \mu \mathrm{M}$; $\mathrm{P}<0.01$ and $\mathrm{P}<0.0001$; Fig. 2A). RT-qPCR revealed an increase in the miR-328 expression levels within A549rCDDP cells compared with their parental cells $(\mathrm{P}<0.05$; Fig. 2B). In addition, the significant elevation of miR-328 expression levels within A549rCDDP cells was accompanied by a decrease in PTEN at the mRNA and protein expression levels compared with A549 cells ( $\mathrm{P}<0.05$; Fig. $2 \mathrm{C}$ and $\mathrm{D})$. These data indicated that the A549rCDDP cell line may be a suitable model to study the effects of miR-328 and PTEN in the development of cisplatin resistance in NSCLC.

PTEN is regulated by miR -328 in A549rCDDP cells. The present study aimed to determine the association between miR-328 and PTEN using a miR-328 inhibitor. As presented in Fig. 3A, miR-328 inhibitor induced a significant decrease in miR-328 expression levels in A549rCDDP cells compared with the miR-NC inhibitor groups $(\mathrm{P}<0.01)$. Additionally, the inhibition of miR-328 significantly increased PTEN mRNA expression and markedly increased the protein expression levels compared with miR-NC inhibitor groups $(\mathrm{P}<0.0001$; Fig. 3B and C). These results indicated that miR-328 may negatively regulate PTEN expression in A549rCDDP cells.

miR-328 directly targets the PTEN 3'UTR. Using the online tool MiRanda, the present study predicted that miR-328 

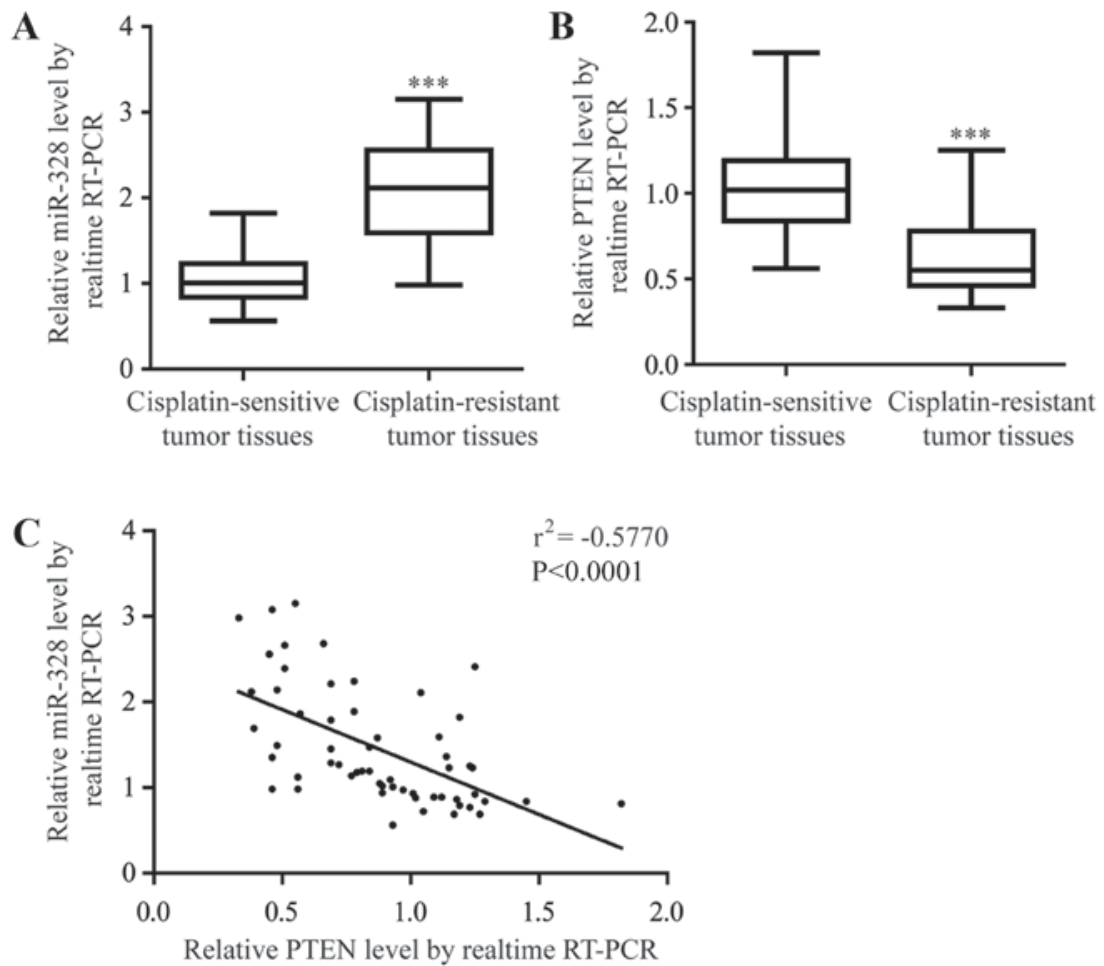

Figure 1. Alterations in miR-328 and PTEN expression in NSCLC tissues from cisplatin-sensitive and cisplatin-resistant patients. Compared with cisplatin-sensitive tumor tissues, (A) elevated miR-328 expression levels and (B) decreased PTEN mRNA expression levels were detected in tumor tissues from cisplatin-resistant NSCLC patients. (C) There was a negative correlation between miR-328 expression and PTEN mRNA expression in the tumor tissues from NSCLC patients. ${ }^{* * * *} \mathrm{P}<0.001$, cisplatin-resistant tumor tissues vs. cisplatin-sensitive tumor tissues. miR, microRNA; NSCLC, non-small cell lung cancer; PTEN, phosphatase and tensin homolog; RT-qPCR, reverse transcription-quantitative polymerase chain reaction.
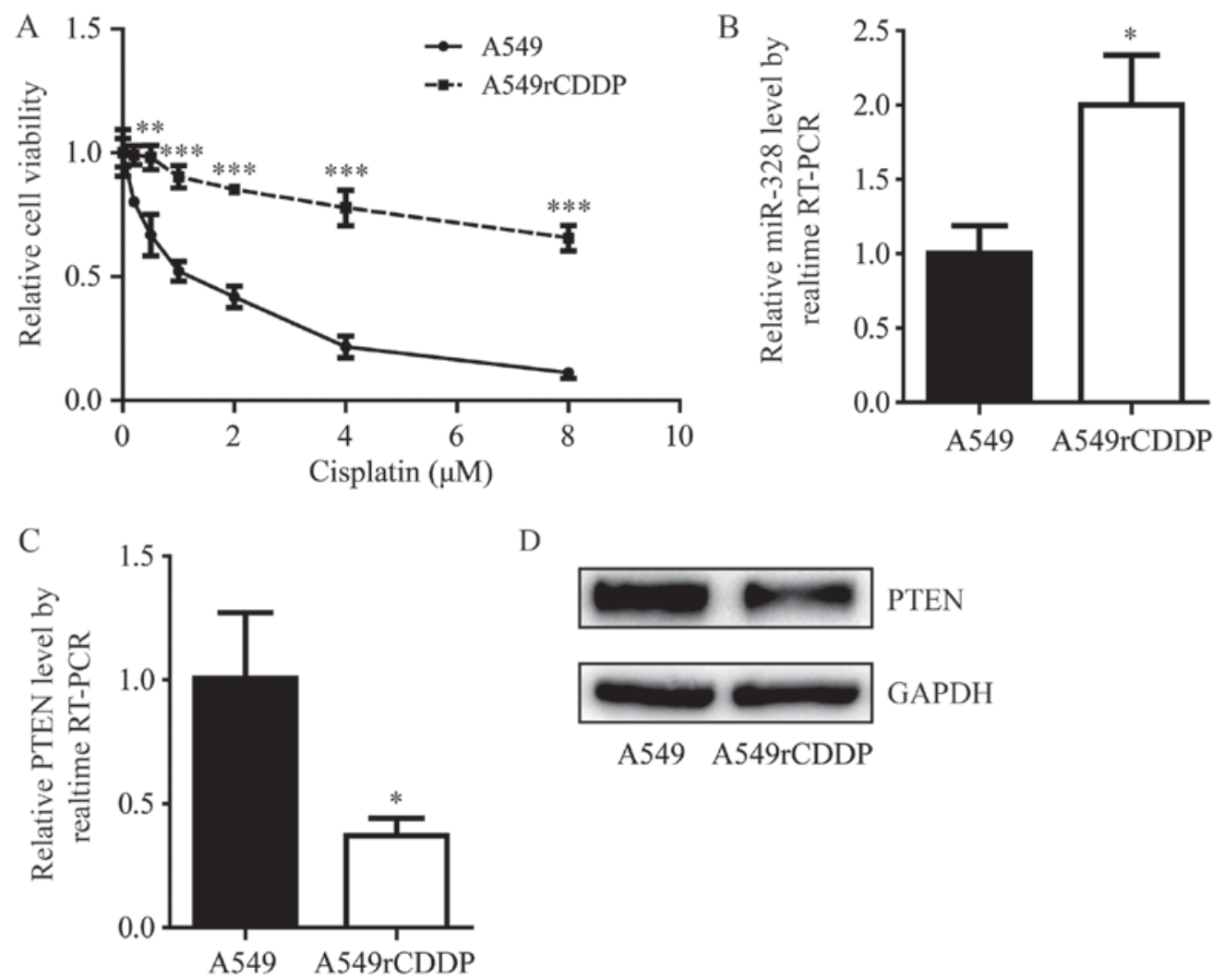

D

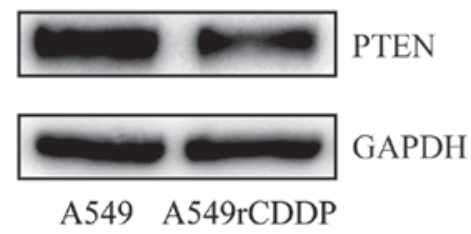

Figure 2. A549rCDDP cells are resistant to cisplatin, with elevations in miR-328 and reductions in PTEN expression levels. (A) A549rCDDP cells were relatively insensitive to treatment with cisplatin compared with A549 cells. (B) Upregulated miR-328 expression levels were detected in A549rCDDP cells compared with A549 cells. PTEN (C) mRNA and (D) protein expression levels were decreased in A549rCDDP cells compared with A549 cells. "P<0.05, ${ }^{* *} \mathrm{P}<0.01$ and ${ }^{* * *} \mathrm{P}<0.001$ vs. A549 cells. A549rCDDP, cisplatin-resistant A549 cells; miR, microRNA; PTEN, phosphatase and tensin homolog; RT-qPCR, reverse transcription-quantitative polymerase chain reaction. 

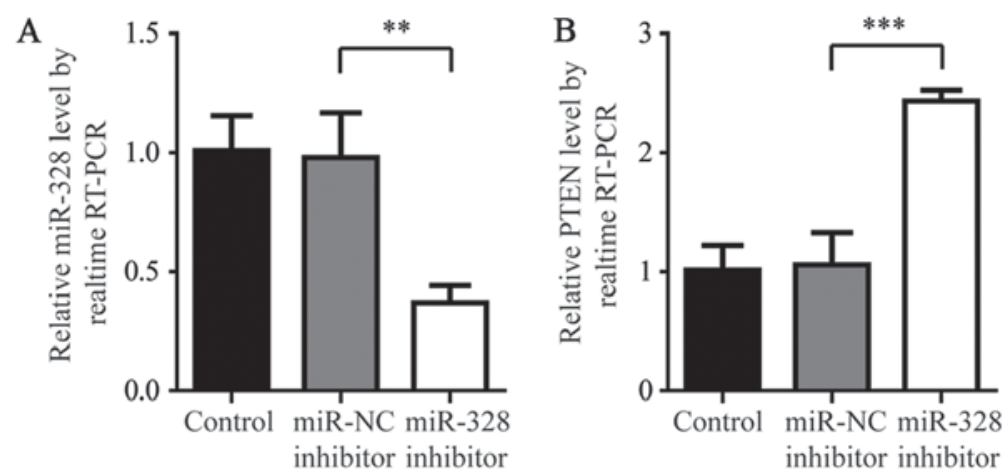

$\mathrm{C}$

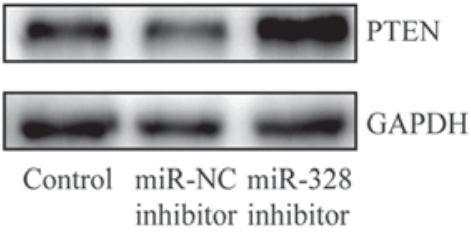

Figure 3. PTEN is negatively regulated by miR-328 in A549rCDDP cells. (A) miR-328 expression levels were decreased in A549rCDDP cells transfected with miR-328 inhibitor compared with cells transfected with miR-NC inhibitor. Transfection of miR-NC inhibitor did not change miR-328 expression in A549rCDDP cells compared with control group. Transfection with miR-328 inhibitor increased the (B) mRNA and (C) protein expression levels of PTEN in A549rCDDP cells compared with cells transfected with miR-NC inhibitor. Transfection of miR-NC inhibitor did not change PTEN (B) mRNA and (C) protein expression in A549rCDDP cells compared with control group. ${ }^{* *} \mathrm{P}<0.01$ and ${ }^{* * *} \mathrm{P}<0.001$, miR-328 inhibitor vs. miR-NC inhibitor, respectively. A549rCDDP, cisplatin-resistant A549 cells; miR, microRNA; NC, negative control; PTEN, phosphatase and tensin homolog; RT-qPCR, reverse transcription-quantitative polymerase chain reaction.

may directly target the 3'UTR of PTEN mRNA (Fig. 4A). A dual-luciferase assay revealed that miR-328 mimics may significantly decrease the luciferase activity of cells transfected with PTEN 3'UTR-WT, although not PTEN 3'UTR-Mut $(\mathrm{P}<0.01$; Fig. 4B). These results indicated that miR-328 may directly target PTEN and reduce the expression of PTEN by binding to its $3^{\prime} \mathrm{UTR}$.

Downregulation of miR-328 reverses cisplatin resistance in A549rCDDP cells. To further confirm the function of miR-328 in the development of cisplatin resistance, A549rCDDP cells were transfected with miR-328 inhibitor in the present study. The antagonist effects of miR-328 did not alter the cell proliferation of A549rCDDP cells compared with the vehicle and miR-NC inhibitor groups (Fig. 5A). However, A549rCDDP cell proliferation was significantly inhibited in the miR-328 inhibitor-transfected group when cells were treated with $1 \mu \mathrm{M}$ cisplatin, compared with that of the vehicleand cisplatin + miR-NC inhibitor groups. This indicated that miR-328 may serve a pivotal role in cisplatin resistance and not in cell proliferation $(\mathrm{P}<0.001$; Fig. $5 \mathrm{~B})$. Additionally, in the presence of cisplatin, miR-328 inhibitor, although not miR-NC inhibitor, induced an elevation in cellular apoptosis; there was no significant difference in the extent of cellular apoptosis between the vehicle + miR-NC inhibitor and cisplatin + miR-NC inhibitor groups (Fig. 5C and D). Collectively, the results of the present study suggested that the upregulation of miR-328 contributed to cisplatin resistance in A549rCDDP cells.

\section{Discussion}

As cisplatin is a first-line drug for the treatment of NSCLC, cisplatin resistance has been considered to be a major issue affecting treatment efficacy for patients with NSCLC (23). The present study identified abnormal overexpression of miR-328 in cisplatin-resistant cells and tumor tissues from patients with cisplatin-resistant NSCLC, suggesting a novel mechanism underlying cisplatin-resistance in NSCLC associated with miR-328.

In addition to its role in the suppression of cell proliferation and migration, PTEN is well known for its function in
A 3'-GUCUCUCCCGGUc-5' miR-328

\section{5'-CAUGGAGGGCCAg-3' PTEN 3'UTR}

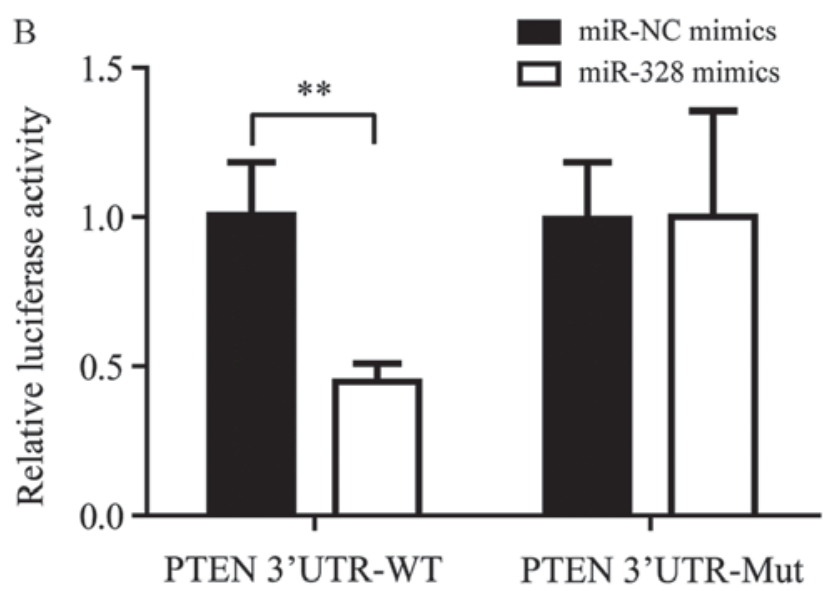

Figure 4. miR-328 directly targets the PTEN 3'UTR. (A) Sequence alignment of miR-328 and the PTEN 3'UTR. (B) In cells transfected with PTEN 3'UTR-WT, co-transfection of miR-328 mimics significantly decreased the luciferase activity compared with cells co-transfected with miR-NC mimics; within cells transfected with PTEN 3'UTR-Mut, no significant difference in luciferase activity was observed between the miR-328 mimics and miR-NC mimics groups. ${ }^{* *} \mathrm{P}<0.01$, miR-328 mimics vs. miR-NC mimics. miR, microRNA; Mut, mutated; Nc, negative control; PTEN, phosphatase and tensin homolog; RT-qPCR, reverse transcription-quantitative polymerase chain reaction; UTR, untranslated region; WT, wild-type.

modulating cancer cell responses to drug treatment $(24,25)$. In NSCLC, promoter methylation was initially reported to account for PTEN silencing, with 35\% of PTEN-negative NSCLC patients exhibiting high levels of promoter methylation (26). In recent years, numerous miRNAs including miR-10a, miR-205 and miR-21 have been reported to negatively regulate PTEN expression at the post-transcriptional level in NSCLC (27-29). Additionally, overexpression of miR-328 was correlated with brain metastasis in patients with NSCLC (13). In vitro studies additionally indicated that miR-328 had the ability to promote 


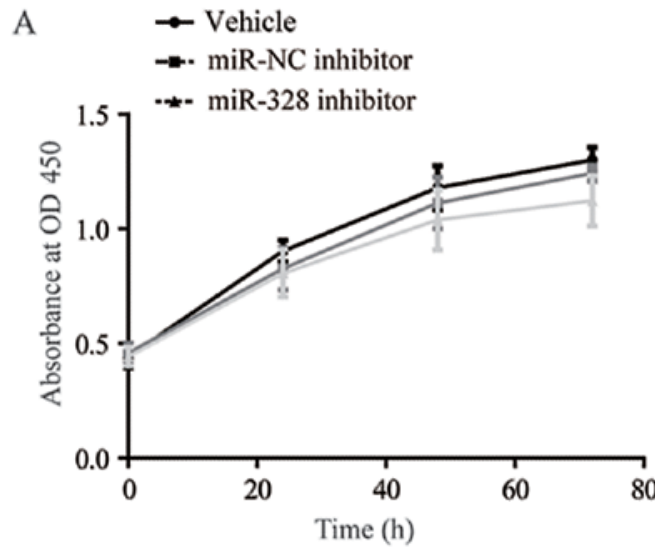

C

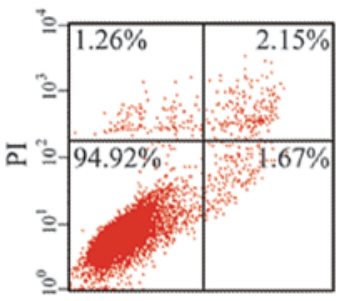

Vehicle+ miR-NC inhibitor

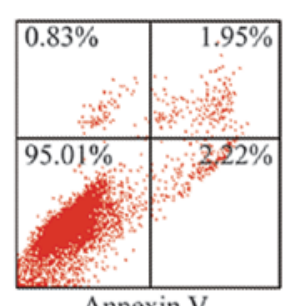

Annexin V miR-NC inhibitor
Cisplatin $(1 \mu \mathrm{M})+$
B

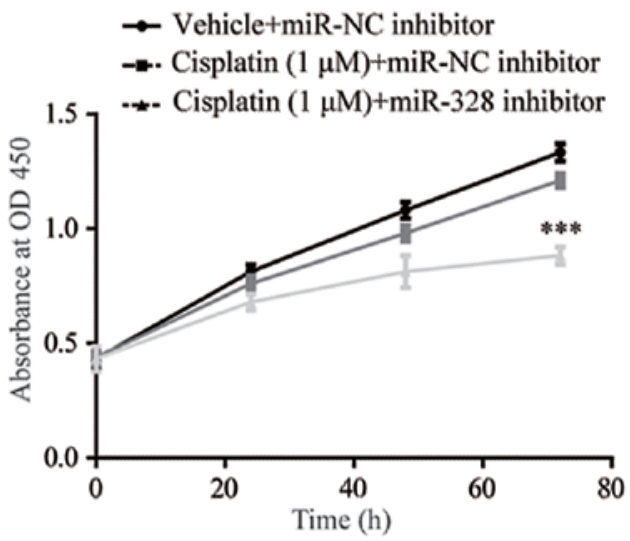

D

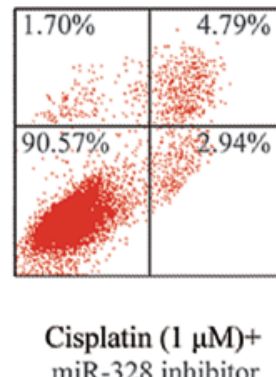

Figure 5. miR-328 may contribute to cisplatin resistance in A549rCDDP cells. (A) Compared with cells of the vehicle and miR-NC inhibitor groups, the proliferation of A549rCDDP cells was unaltered following transfection with miR-328 inhibitor. Following treatment with $1 \mu \mathrm{M}$ cisplatin, (B) proliferation was inhibited in response to transfection with miR-328 inhibitor and (C) apoptosis was induced in A549rCDDP cells when compared with the rates in the miR-NC inhibitor group. No significant differences in the rates of cellular apoptosis between the vehicle + miR-NC inhibitor and cisplatin + miR-NC inhibitor groups were observed. (D) Quantitative analysis of apoptosis data. ${ }^{* * *} \mathrm{P}<0.001$, miR-328 inhibitor vs. miR-NC inhibitor. FITC, fluorescein isothiocyanate; miR, microRNA; NC, negative control; OD, optical density; PI, propidium iodide.

A549 cell invasion and migration (30). The present study observed an upregulation in miR-328 and a downregulation in PTEN expression levels within cisplatin-resistant NSCLC cells and tumor tissues from cisplatin-resistant NSCLC patients. Furthermore, PTEN may be negatively regulated by miR-328 in NSCLC cells; miR-328 inhibition may reverse cisplatin resistance in NSCLC cells as observed in the present study. Thus, miR-328 may be considered to be an inducer of cisplatin resistance in NSCLC cells via PTEN targeting.

In conclusion, the present study demonstrated that dysregulation of miR-328 was associated with cisplatin resistance in NSCLC. Mechanistically, miR-328 may directly bind to the 3'UTR of PTEN to negatively regulate PTEN expression in NSCLC cells. The results of the present study proposed miR-328 as a novel prognostic marker and therapeutic target in patients with NSCLC exhibiting cisplatin resistance.

\section{Acknowledgements}

Not applicable.

\section{Funding}

Not applicable.

\section{Availability of data and materials}

The datasets used and/or analyzed during the current study are available from the corresponding author on reasonable request.

\section{Authors' contributions}

CW, SW and FM participated in the design and performance of the experiments; WZ and CW contributed to the collection of samples and clinical data; and WZ supervised and wrote the manuscript.

\section{Ethics approval and consent to participate}

All procedures performed in the present study involving human participants were approved by the Ethics Committee of Dezhou People's Hospital.

\section{Patient consent for publication}

Written informed consent for the publication of any associated data and accompanying images was provided by all patients prior to surgery. 


\section{Competing interests}

The authors declare that they have no competing interests.

\section{References}

1. Jemal A, Bray F, Center MM, Ferlay J, Ward E and Forman D: Global cancer statistics. CA Cancer J Clin 61: 69-90, 2011.

2. Siegel RL, Miller KD and Jemal A: Cancer statistics, 2016. CA Cancer J Clin 66: 7-30, 2016.

3. Dasari S and Tchounwou PB: Cisplatin in cancer therapy: Molecular mechanisms of action. Eur J Pharmacol 740: 364-378, 2014.

4. Tan XL, Moyer AM, Fridley BL, Schaid DJ, Niu N, Batzler AJ, Jenkins GD, Abo RP, Li L, Cunningham JM, et al: Genetic variation predicting cisplatin cytotoxicity associated with overall survival in lung cancer patients receiving platinum-based chemotherapy. Clin Cancer Res 17: 5801-5811, 2011.

5. Schiller JH, Harrington D, Belani CP, Langer C, Sandler A, Krook J, Zhu J and Johnson DH; Eastern Cooperative Oncology: Comparison of four chemotherapy regimens for advanced non-small-cell lung cancer. N Engl J Med 346: 92-98, 2002.

6. Bartel DP: MicroRNAs: Genomics, biogenesis, mechanism, and function. Cell 116: 281-297, 2004.

7. Hesse $M$ and Arenz C: MicroRNA maturation and human disease. Methods Mol Biol 1095: 11-25, 2014.

8. Gommans WM and Berezikov E: Controlling miRNA regulation in disease. Methods Mol Biol 822: 1-18, 2012.

9. Romero-CordobaSL,Salido-GuadarramaI,Rodriguez-DorantesM and Hidalgo-Miranda A: miRNA biogenesis: Biological impact in the development of cancer. Cancer Biol Ther 15: 1444-1455, 2014.

10. Shin VY and Chu KM: MiRNA as potential biomarkers and therapeutic targets for gastric cancer. World J Gastroenterol 20 10432-10439, 2014.

11. Saberi A, Danyaei A, Neisi N, Dastoorpoor M and Tahmasbi Birgani MJ: MiR-328 may be considered as an oncogene in human invasive breast carcinoma. Iran Red Crescent Med J 18: e42360, 2016.

12. Luo X, Yang S, Zhou C, Pan F, Li Q and Ma S: MicroRNA-328 enhances cellular motility through posttranscriptional regulation of PTPRJ in human hepatocellular carcinoma. Onco Targets Ther 8: 3159-3167, 2015.

13. Arora S, Ranade AR, Tran NL, Nasser S, Sridhar S, Korn RL, Ross JT, Dhruv H, Foss KM, Sibenaller Z, et al: MicroRNA-328 is associated with (non-small) cell lung cancer (NSCLC) brain metastasis and mediates NSCLC migration. Int J Cancer 129: 2621-2631, 2011.

14. Steck PA, Pershouse MA, Jasser SA, Yung WK, Lin $\mathrm{H}$, Ligon AH, Langford LA, Baumgard ML, Hattier T, Davis T, et al: Identification of a candidate tumour suppressor gene, MMAC1, at chromosome 10q23.3 that is mutated in multiple advanced cancers. Nat Genet 15: 356-362, 1997.

15. Hopkins BD, Hodakoski C, Barrows D, Mense SM and Parsons RE: PTEN function: The long and the short of it. Trends Biochem Sci 39: 183-190, 2014.

16. Song MS, Salmena L and Pandolfi PP: The functions and regulation of the PTEN tumour suppressor. Nat Rev Mol Cell Biol 13: 283-296, 2012.
17. McCubrey JA, Steelman LS, Chappell WH, Abrams SL, Franklin RA, Montalto G, Cervello M, Libra M, Candido S, Malaponte G, et al: Ras/Raf/MEK/ERK and PI3K/PTEN/Akt/mTOR cascade inhibitors: How mutations can result in therapy resistance and how to overcome resistance. Oncotarget 3: 1068-1111, 2012.

18. Chalhoub $\mathrm{N}$ and Baker SJ: PTEN and the PI3-kinase pathway in cancer. Annu Rev Pathol 4: 127-150, 2009.

19. Therasse P, Arbuck SG, Eisenhauer EA, Wanders J, Kaplan RS, Rubinstein L, Verweij J, Van Glabbeke M, van Oosterom AT, Christian MC and Gwyther SG: New guidelines to evaluate the response to treatment in solid tumors. European organization for research and treatment of cancer, National cancer institute of the United States, National cancer institute of Canada. J Natl Cancer Inst 92: 205-216, 2000.

20. Travis WD, Brambilla E, Nicholson AG, Yatabe Y, Austin JHM, Beasley MB, Chirieac LR, Dacic S, Duhig E, Flieder DB, et al: The 2015 World Health Organization classification of lung tumors: Impact of genetic, clinical and radiologic advances since the 2004 classification. J Thorac Oncol 10: 1243-1260, 2015.

21. Livak KJ and Schmittgen TD: Analysis of relative gene expression data using real-time quantitative PCR and the 2(-Delta Delta C(T)) method. Methods 25: 402-408, 2001.

22. Cao L, Chen J, Ou B, Liu C, Zou Y and Chen Q: GAS5 knockdown reduces the chemo-sensitivity of non-small cell lung cancer (NSCLC) cell to cisplatin (DDP) through regulating miR-21/PTEN axis. Biomed Pharmacother 93: 570-579, 2017.

23. Galluzzi L, Vitale I, Michels J, Brenner C, Szabadkai G, Harel-Bellan A, Castedo M and Kroemer G: Systems biology of cisplatin resistance: Past, present and future. Cell Death Dis 5: e1257, 2014.

24. Zheng P, Chen L, Yuan X, Luo Q, Liu Y, Xie G, Ma Y and Shen L: Exosomal transfer of tumor-associated macrophage-derived miR-21 confers cisplatin resistance in gastric cancer cells. J Exp Clin Cancer Res 36: 53, 2017.

25. Gschwantler-Kaulich D, Tan YY, Fuchs EM, Hudelist G, Köstler WJ, Reiner A, Leser C, Salama M, Attems J, Deutschmann C, et al: PTEN expression as a predictor for the response to trastuzumab-based therapy in Her-2 overexpressing metastatic breast cancer. PLoS One 12: e0172911, 2017.

26. Soria JC, Lee HY, Lee JI, Wang L, Issa JP, Kemp BL, Liu DD, Kurie JM, Mao L and Khuri FR: Lack of PTEN expression in non-small cell lung cancer could be related to promoter methylation. Clin Cancer Res 8: 1178-1184, 2002.

27. Yu T, Liu L, Li J, Yan M, Lin H, Liu Y, Chu D, Tu H, Gu A and Yao M: MiRNA-10a is upregulated in NSCLC and may promote cancer by targeting PTEN. Oncotarget 6: 30239-30250, 2015

28. Lei L, Huang Y and Gong W: miR-205 promotes the growth, metastasis and chemoresistance of NSCLC cells by targeting PTEN. Oncol Rep 30: 2897-2902, 2013.

29. Zhang JG, Wang JJ, Zhao F, Liu Q, Jiang K and Yang GH: MicroRNA-21 (miR-21) represses tumor suppressor PTEN and promotes growth and invasion in non-small cell lung cancer (NSCLC). Clin Chim Acta 411: 846-852, 2010.

30. Du C, Zheng J, Lu X and Wang Y: Downregulation of miR-18a or miR-328 inhibits the invasion and migration of lung adenocarcinoma A549 cells. Xi Bao Yu Fen Zi Mian Yi Xue Za Zhi 32: 1051-1054, 2016 (In Chinese). 